\title{
RADIAÇÃO SOLAR E SALDO DE RADIAÇÃO EM CULTIVO DE CAFÉ A PLENO SOL E CONSORCIADO COM BANANA ‘PRATA ANA $\tilde{A}^{\prime(1)}$
}

\author{
JOSÉ RICARDO MACEDO PEZZOPANE ${ }^{(2,4)}$; MÁRIO JOSÉ PEDRO JÚNIOR ${ }^{(2)}$; \\ PAULO BOLLER GALLO ${ }^{(3)}$
}

\begin{abstract}
RESUMO
Medições da radiação solar global e do saldo de radiação foram realizadas em cafeeiros (Coffea arabica L.) cv. Icatu Vermelho IAC 4045, cultivados a pleno sol e consorciados com bananeira (Musa AAB)

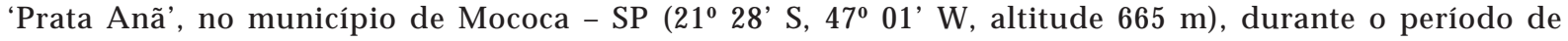
outubro de 2001 a setembro de 2002, com o objetivo de quantificar a atenuação da radiação solar e do saldo de radiação em sistema de produção de café consorciado. Os resultados obtidos mostraram diferenças nos elementos medidos nos dois sistemas de cultivo. Houve atenuação média dos valores de radiação solar global em cultivo de café consorciado com banana 'Prata Anã' da ordem de 21\%, com variação mensal de $16 \%$ a $27 \%$, tendo sido verificadas diferenças de atenuação da radiação solar nos diferentes pontos amostrais do sistema consorciado. Em relação ao saldo de radiação, verificou-se redução média de $16 \%$ nos valores diários no cultivo consorciado em comparação ao cultivo a pleno sol. O saldo de radiação representou $50 \%$ da radiação solar global no cultivo a pleno sol, com variação mensal de $34 \%$ a $62 \%$, e no cultivo consorciado o saldo de radiação representou $53 \%$ da radiação solar global, com variação de 35 a $38 \%$.
\end{abstract}

Palavras chave: radiação solar global, microclima, consorciação, Coffea arabica .

\section{ABSTRACT \\ SOLAR AND NET RADIATION IN A COFFEE CROP GROWN UNSHADED AND SHADED BY 'PRATA ANÃ' BANANA PLANTS}

\begin{abstract}
Microclimatic measurements (incoming solar radiation and net radiation) were taken from October, 2001 to September, 2002 in a coffee crop (Coffea arabica L.) cv. Icatu Vermelho IAC 4045, shaded by banana

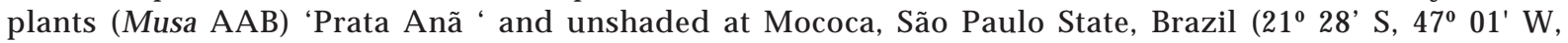
altitude $665 \mathrm{~m}$ ), aiming at evaluating the reduction of the solar and net radiation for the different crop conditions. The obtained results showed differences for the different crop conditions. The banana plants reduced the incoming solar radiation to the coffee crop by $21 \%$, with monthly variation from $16 \%$ to $27 \%$. Differences were also found concerning the reduction of the incoming solar radiation in different points of the shaded crop. The net radiation was reduced by $16 \%$ in the daily values in the shaded plants in comparisom to the unshaded ones. The net radiation represented $50 \%$ of the incoming solar radiation in the unshaded crop, with monthly variation from $34 \%$ to $62 \%$, and in the plots shadded by banana, the net radiation represented $53 \%$ of the incoming solar radiation, with variation from 35 to $38 \%$.
\end{abstract}

Key words: solar radiation, microclimate, shadding, Coffea arabica.

$\left({ }^{1}\right)$ Extraído da Tese de Doutorado do primeiro autor apresentada à Escola Superior de Agricultura "Luiz de Queiroz", Piracicaba, SP. Recebido para publicação em 26 de novembro de 2004 e aceito em 17 de maio de 2005.

(2) Instituto Agronômico (IAC), Caixa Postal 28, 13012-970 Campinas (SP). E-mail: rpezzo@iac.sp.gov.br

( $\left.{ }^{3}\right)$ Pólo Regional de Desenvolvimento Tecnológico dos Agronegócios do Nordeste Paulista (DDD/APTA/SAA), Caixa Postal 58, 13730-970 Mococa (SP).

$\left({ }^{4}\right)$ Bolsista FAPESP. 


\section{INTRODUÇÃO}

Em sistemas arborizados e policultivos, em função da natureza heterogênea de seus componentes, diferentes organismos compartilham o mesmo espaço, o ambiente físico afeta e interage de modo complexo ao longo das fases de seu ciclo, com reflexos no crescimento, no manejo e nas interações entre seus componentes.

A radiação solar é um dos principais elementos meteorológicos modificados na consorciação de cultivos.

Os estudos microclimáticos realizados em sistemas consorciados necessitam enfocar medidas de radiação solar global e saldo de radiação, uma vez que esses elementos determinam a disponibilidade de energia para processos como evapotranspiração, aquecimento do ar e solo e fotossíntese.

Dentre as principais culturas produzidas em agrossistemas arborizados ou consorciados, o café é das mais estudadas (BARRADas e Fanjul, 1986; Beer, 1987; Caramori et al., 1996). Para a cultura do cafeeiro, o uso de sistemas consorciados visa minimizar a exposição das plantas a riscos climáticos como geadas, excessos de radiação solar, temperaturas elevadas e ventos excessivos. Essas alterações podem contribuir para aumento da sustentabilidade da lavoura (Matiello e Almeida, 1991).

Vários autores estudaram o efeito do sombreamento natural no cultivo de café enfocando o microclima da cultura, crescimento de plantas, produtividade e qualidade da bebida (BARRADAS e FAnjul, 1986; Baggio et al., 1997; Miguel et al., 1995; BeEr et al., 1998; PeETERs et al., 2002). Nesses trabalhos, os autores descrevem o sombreamento de maneira qualitativa, seja pelo tipo de árvore utilizada, seja pela densidade de plantio da cultura intercalar, porém poucos autores determinaram a quantidade de interceptação de maneira quantitativa, como é o caso dos trabalhos de Pezzopane et al. (2003), em um sistema consorciado de cafeeiro com coqueiro-anão verde e de FArfan-VALENCIA et al. (2003), em sistemas arborizados de café na Colômbia.

Com o objetivo de quantificar a atenuação da energia radiante e o balanço de radiação em sistemas de produção de café consorciado, foram realizadas observações da radiação solar global e do saldo de radiação em sistema de produção de café a pleno sol e consorciado com banana 'Prata Anã' no município de Mococa (SP).

\section{MATERIAL E MÉTODOS}

Foram realizadas observações de radiação solar global (RG) e de saldo de radiação (SR) durante o período de outubro de 2001 a setembro de 2002, em um sistema de produção consorciado de café (Coffea arabica L.) cv. Icatu Vermelho IAC 4045 enxertado sobre cV. Apoatã IAC 2258, com três anos de idade, cultivado a pleno sol e consorciado com banana (Musa AAB) 'Prata Anã', no Pólo Regional de Desenvolvimento Tecnológico dos Agronegócios do Nordeste Paulista - APTA, em Mococa, SP (21 $28^{\prime}$ S, $47^{\circ} 01^{\prime} \mathrm{W}$, altitude $665 \mathrm{~m}$ ).

O espaçamento das plantas de café nos dois sistemas de cultivo era de $4 \times 1 \mathrm{~m}$ e altura aproximada de $1,8 \mathrm{~m}$; das bananeiras, de $8 \times 8 \mathrm{~m}$, altura aproximada de $4,5 \mathrm{~m}$, totalizando 156 planta/hectare (Figura 1, esquerda). Os sistemas de produção constituíam parcelas de $40 \times 40 \mathrm{~m}$, em mesma condição topográfica e de orientação de encosta (nordeste), com baixa declividade.

O manejo da cultura do café foi realizado com os tratos culturais de acordo com as instruções técnicas para a região (THOMAZIELLo et al., 2000) e para a cultura da bananeira seguiram-se as recomendações de Moreira (1987).

Nas bananeiras, ressalta-se a realização da técnica do desbaste, feita para favorecer o maior desenvolvimento e a produção da planta, eliminandose os pés que já produziram e os excessos de brotação para as produções seguintes. Durante o período experimental, foram realizados desbastes na bananeiras nas seguintes datas: 20/12/2001, 8/3/ 2002 e 10/10/2002.

A radiação solar global foi obtida com tubos solarímetros (TSL, Delta T Devices), instalados acima do dossel da cultura de café (1,9 m de altura). O saldo de radiação foi obtido com saldo-radiômetros (Q7, REBS e NR-Lite, Keppen \& Zonen) instalados a, aproximadamente $3 \mathrm{~m}$ de altura.

Na figura 1 (direita), é apresentado um esquema com a disposição dos sensores na parcela do cultivo consorciado. A amostragem da radiação solar global foi feita na forma de quadrante em quatros pontos do sistema (Pontos amostrais 1 a 4), conforme realizada por WALLACE (1996) em um sistema agroflorestal de grevílea com milho e FARFAN-VALENCIA et al. (2003) para sistemas agroflorestais de café. O saldo de radiação foi amostrado na parcela do pleno sol e em três pontos do sistema consorciado (Pontos amostrais 1 a 3 ). 


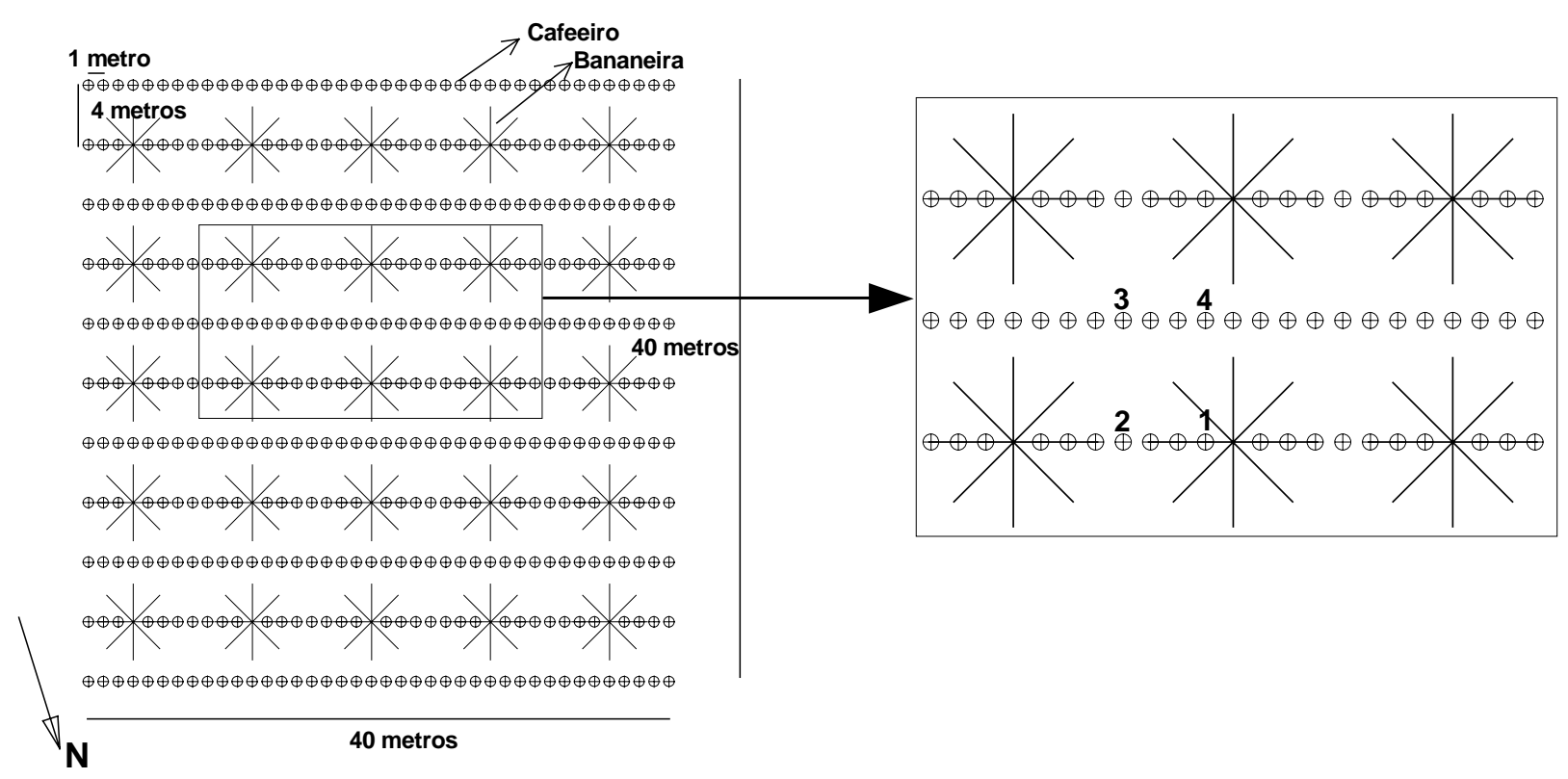

Figura 1. Representação esquemática de instalação de sensores na parcela consorciada.

Os sensores foram acoplados a um sistema automático de aquisição de dados (CR10X, Campbell Scientific Inc.), tendo sido programado para leituras a cada 20 segundos, médias a cada 15 minutos (W $\left.\mathrm{m}^{-2}\right)$ e posterior integração diária $\left(\mathrm{MJ} \mathrm{m}^{-2} \mathrm{dia}^{-1}\right)$.

Para a representação da radiação solar global no cultivo a pleno sol, foram obtidos dados de incidência dessa variável no posto meteorológico situado a aproximadamente $500 \mathrm{~m}$ do experimento.

\section{RESULTADOS E DISCUSSÃO}

Na tabela 1, são apresentados os valores médios mensais da incidência da radiação solar global (RG) no cultivo a pleno sol e nos quatro pontos amostrais do sistema consorciado no período de outubro de 2001 a setembro de 2002. Na figura 2, é apresentada a variação sazonal da relação entre a radiação solar global nos quatro pontos do cultivo consorciado, bem como a média dos pontos amostrais e a da radiação solar global no cultivo a pleno sol.

Pelos resultados, verifica-se que as plantas de bananeira Prata Anã, utilizadas no sistema de cultivo consorciado, promoveram uma atenuação na transmissividade da radiação solar global até a altura das plantas de café. Os valores médios de RG mostraram diferenças quando comparados os vários pontos amostrais dentro do sistema consorciado. No ponto amostral 1, próximo às bananeiras, a transmissividade foi mais influenciada, variando entre $35 \%$ e $69 \%$, com maiores atenuações ocorrendo no período de fevereiro a julho. No ponto 2, situado entre duas bananeiras, a transmissividade variou entre $77 \%$ e $94 \%$, sendo a atenuação maior no período de março a junho. Nos pontos 3 e 4 (linha central de cafeeiros), a atenuação foi menor, com a relação entre a radiação solar no cultivo consorciado e no cultivo a pleno sol sempre superior a $80 \%$.

Quando analisada a média dos quatro pontos amostrais, observou-se variação temporal na transmissividade da RG, com variação mensal de $75 \%$ a $84 \%$, influenciada principalmente pelos pontos amostrais 1 e 2 do sistema consorciado. As maiores atenuações ocorreram no período de janeiro a julho e as maiores transmissividades de agosto a dezembro. Explica-se essa variação pelo aumento do ângulo zenital que ocorre de outono e inverno nas condições de cultivo do hemisfério sul, fazendo com que as plantas de banana próximas a esses pontos amostrais interceptem radiação por um maior período do dia em relação aos outros meses do ano.

Convém ressaltar que o desbaste das bananeiras, ocorrido de dezembro de 2001 e março de 2002, pouco influenciou a interceptação da radiação solar global, tendo sido observada maior influencia no segundo período de podas, quando ocorreu pequena elevação na relação entre a radiação solar medida nos dois sistemas em março e abril de 2002. FARFAN-VALENCIA et at. (2003) e BLACK e ONG (2000) relatam que em cultivo arborizados de café, a transmissividade da radiação solar está relacionada com a época do ano, arquitetura da planta sombreadora e o arranjo espacial utilizado. 
Tabela 1. Valores médios mensais de radiação solar global ( $\left.\mathrm{MJ} \mathrm{m}^{-2} \mathrm{dia}^{-1}\right)$ em cultivo de café a pleno sol e em diferentes pontos amostrais de cultivo de café consorciado com bananeira Prata Anã, em Mococa (SP), no período de outubro de 2001 a setembro de 2002

\begin{tabular}{|c|c|c|c|c|c|c|}
\hline \multirow{3}{*}{ Mês } & \multirow{3}{*}{ Pleno sol } & \multicolumn{5}{|c|}{ Radiação solar global (MJ m ${ }^{-2}$ dia $^{-1}$ ) } \\
\hline & & \multicolumn{5}{|c|}{ Cultivo consorciado } \\
\hline & & Ponto 1 & Ponto 2 & Ponto 3 & Ponto 4 & Média ${ }^{(1)}$ \\
\hline Outubro & 21,3 & 14,8 & 17,7 & 18,6 & 19,0 & 17,5 \\
\hline Novembro & 19,4 & 13,3 & 17,4 & 16,9 & 17,7 & 16,3 \\
\hline Dezembro & 19,0 & 10,3 & 17,9 & 16,9 & 17,5 & 15,6 \\
\hline Janeiro & 21,1 & 8,9 & 19,6 & 19,3 & 19,5 & 16,8 \\
\hline Fevereiro & 17,4 & 6,5 & 14,5 & 15,5 & 15,4 & 13,0 \\
\hline Março & 20,7 & 8,7 & 16,0 & 19,3 & 18,9 & 15,7 \\
\hline Abril & 20,2 & 8,3 & 16,8 & 19,2 & 18,0 & 15,6 \\
\hline Maio & 15,0 & 6,4 & 11,9 & 12,8 & 13,1 & 11,1 \\
\hline Junho & 15,6 & 6,4 & 12,6 & 12,8 & 14,1 & 11,5 \\
\hline Julho & 14,6 & 5,3 & 13,2 & 12,8 & 13,0 & 11,1 \\
\hline Agosto & 16,7 & 8,4 & 15,2 & 15,0 & 14,8 & 13,4 \\
\hline Setembro & 17,2 & 10,5 & 14,4 & 15,8 & 15,6 & 14,2 \\
\hline
\end{tabular}

$\left({ }^{1}\right)$ Média dos pontos amostrais dentro da parcela consorciada

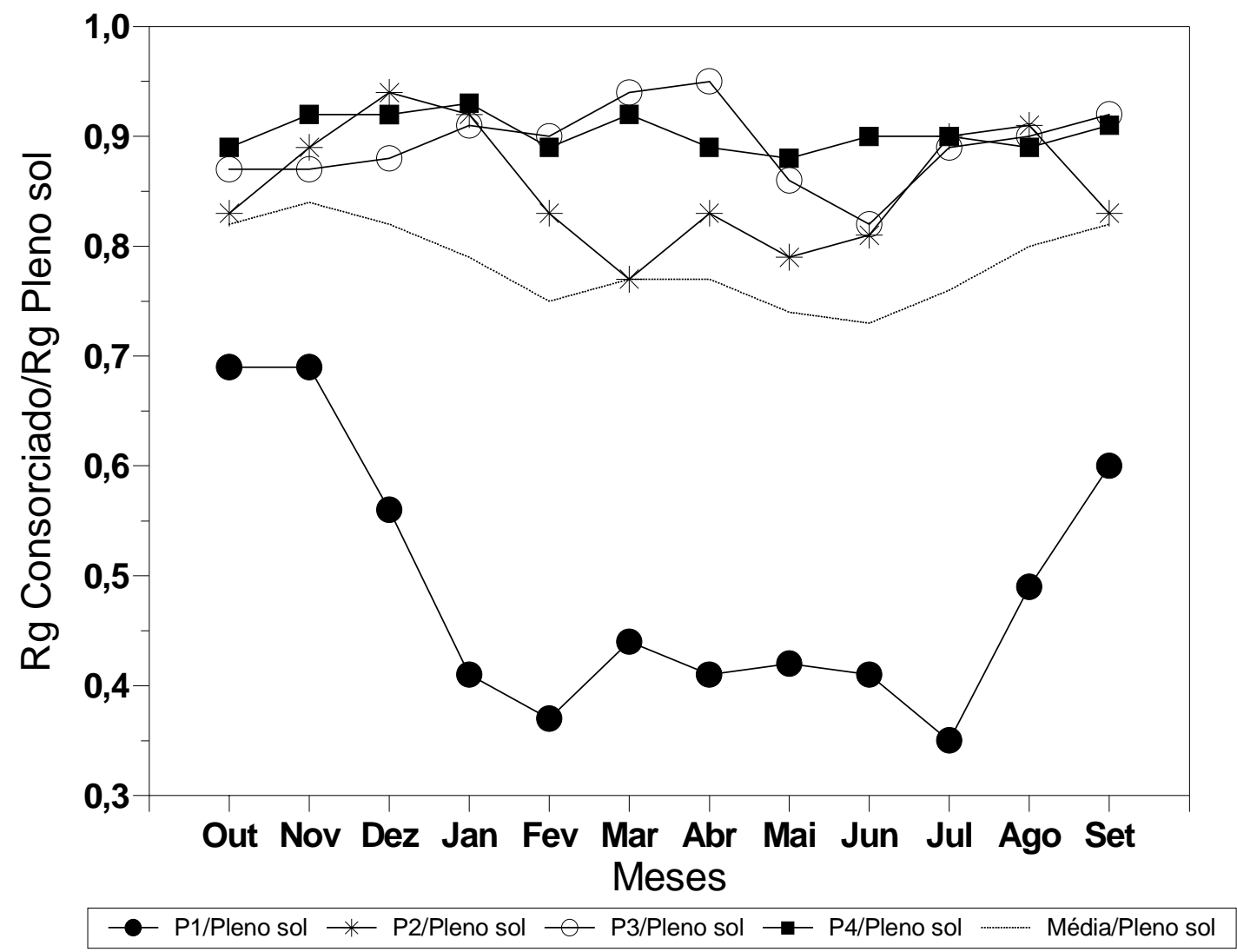

Figura 2. Variação sazonal da relação entre a radiação solar global no cultivo de café consorciado (RG consorciado) e no cultivo de café a pleno sol (RG Pleno sol), em Mococa (SP), no período de outubro de 2001 a setembro de 2002. 
Os diferentes valores de RG obtidos na comparação entre os pontos estudados dentro do sistema consorciado evidenciam uma variação espacial do balanço de radiação. $\mathrm{Na}$ Figura 3 é mostrada a incidência de radiação solar global em quatro episódios, em dias de céu limpo, selecionados para os dois sistemas de cultivo.

$$
\text { Em 6/11/2001 (Figura 3A), a }
$$
interceptação de radiação solar praticamente só ocorreu no ponto 2 , no total de $13 \%$ durante o dia, e no ponto 1 , com $29 \%$; no ponto amostral 2, a interceptação mais significativa ocorreu no período até as 11 horas, enquanto no ponto 1 , a partir das 11 horas.

Fato semelhante ocorreu em 5/2/2002 (Figura 3B), sendo verificada maior atenuação no ponto 1 , já a partir das 10 horas da manhã, totalizando $66 \%$ de RG interceptada. Em fevereiro, verificou-se transmissividade de $37 \%$ da RG para esse ponto amostral. Nos pontos 3 e 4, para estes episódios, a interceptação só ocorreu no período da manhã e no fim da tarde.
Em 15/6/2002 (Figura 3C), a interceptação foi mais significativa, principalmente nos pontos $1,2 \mathrm{e}$ 3. No ponto amostral 1, a transmissividade foi baixa desde as 10 horas da manhã. No ponto 2 , a atenuação ocorreu no período da tarde e no ponto 3, de manhã até ao meio-dia. Em junho houve as maiores interceptações, com média mensal de 27\%. Em 18/8/ 2002 (Figura 3D), observaram-se semelhanças de interceptação com o episódio de fevereiro, apenas com diferença na quantidade de interceptação do ponto 1 , que foi menor nesse episódio. Por outro lado, no ponto 2, nesse episódio, verificou-se maior interceptação no período da tarde.

A maior atenuação de radiação no ponto 1, observada sempre no período vespertino, em todos os episódios, pode estar relacionada com a exposição da parcela consorciada, orientada na face Nordeste. A diferença de transmissividade entre os diferentes pontos amostrais e as épocas do ano, verificada na Figura 3, pode ser explicada pela variação da trajetória aparente do sol; as maiores variações ocorreram nos pontos 1 (situado próximo à bananeira) e 2 (situado entre duas bananeiras).
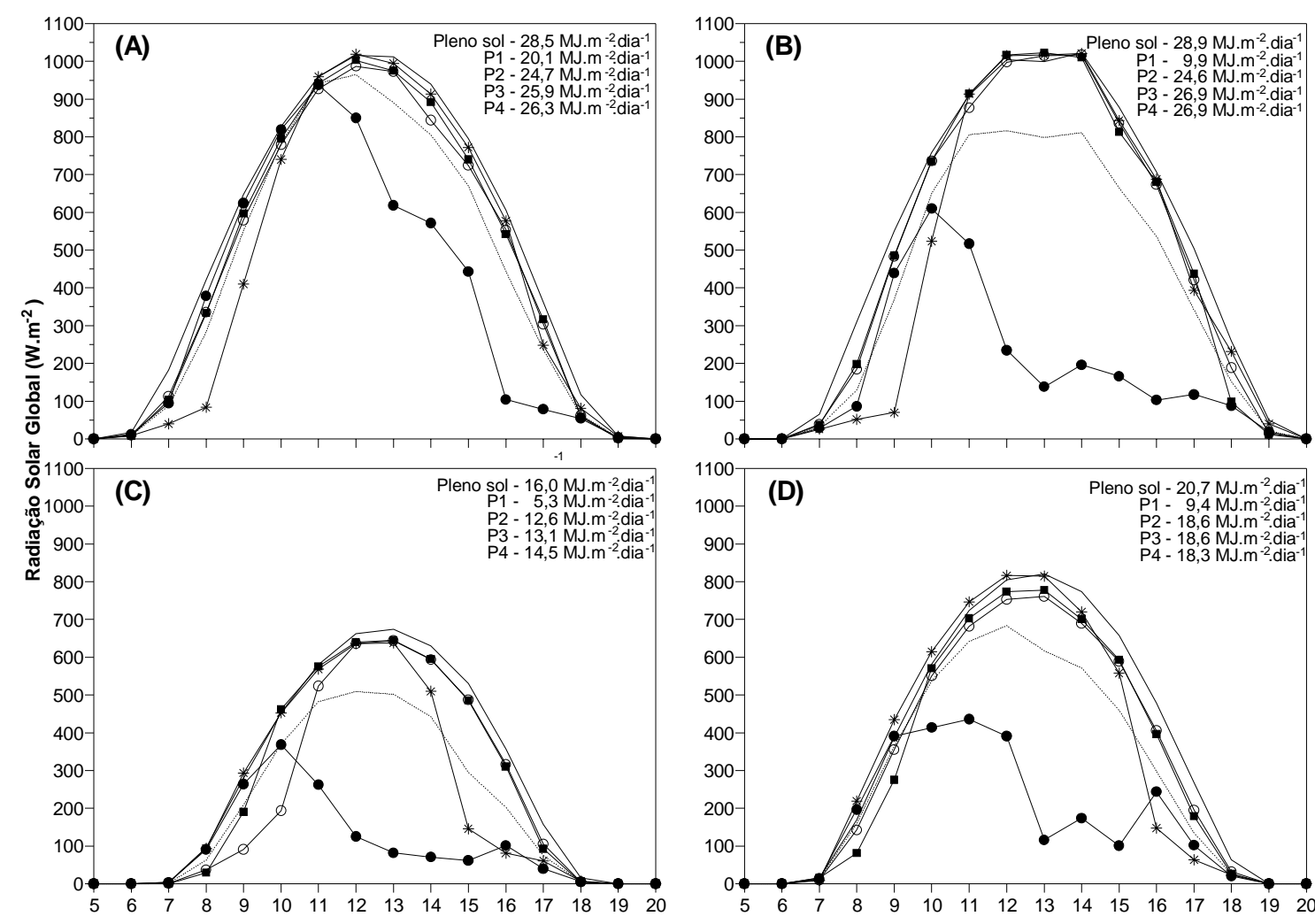

Hora do dia

- Pleno sol - - Ponto $1+$ Ponto $2-$ Ponto $3-$ Ponto $4 \quad$ Média Consorciado

Figura 3. Variação dos valores horários da radiação solar global (RG) em cultivo de café a pleno sol e em diferentes pontos amostrais de cultivo de café consorciado com banana Prata Anã, em Mococa (SP), em 6/11/2001 (A), 5/2/ 2002 (B), 15/6/2002 (C) e 18/8/2002 (D). 
A comparação dos valores diários obtidos da RG (cultivo a pleno sol) e da transmitida nos diferentes pontos de medição da parcela consorciada (média dos pontos amostrais) está apresentada na figura 4 . O coeficiente angular $(0,79)$ indica uma redução média da transmissividade de $21 \%$, promovida pelas plantas de bananeira no cultivo consorciado.

Pezzopane et al. (2003), em trabalho realizado com cultivo consorciado de café com coqueiro anão verde na região de Garça, SP, obtiveram valores de atenuação da radiação solar incidente nas plantas de café em torno de $42 \%$ ao longo do ano. FARFANVALENCIA et al. (2003) obtiveram porcentagens médias de radiação fotossiteticamente ativa transmitida sobre plantas de café em sistemas agroflorestais na Colômbia entre $45 \%$ e $55 \%$ para a espécie Cordia alliodora; $30 \%$ a $49 \%$ em Pinus oocarpa e $64 \%$ a $68 \%$ em Eucalyptus grandis. Camargo e Pereira (1994) relatam que árvores de sombreamento em cultivos arborizados de café em regiões tropicais devem cobrir cerca de $20 \%$ da superfície; excessos de sombreamento podem ser prejudiciais ao desenvolvimento e produção dos cafeeiros, como o ocorrido nos experimentos de Carvalho et al. (1961) e Carvajal (1984), citado por Camargo e Pereira (1994).

Na tabela 2 estão apresentados os valores médios mensais do saldo de radiação (SR) no cultivo a pleno sol e em três pontos amostrais (pontos amostrais 1 a 3 ) do sistema consorciado no período de outubro de 2001 a setembro de 2002. Na Figura 5 é apresentada a relação média mensal entre os valores diários do saldo de radiação nos três pontos do sistema consorciado, bem como sua média e o SR no cultivo a pleno sol para o mesmo período. Pode ser verificado que as bananeiras utilizadas no consórcio promoveram alteração no saldo de radiação em comparação ao cultivo a pleno sol, o que poderia induzir alterações dos fluxos de calor sensível, latente e de calor para o solo (Pezzopane, 2001). No ponto 1 do sistema consorciado, próximo à bananeira, o saldo de radiação foi mais influenciado, principalmente a partir de janeiro de 2002, quando permaneceu em média, entre $19 \%$ a $39 \%$ do SR no cultivo a pleno sol até setembro de 2002, evidenciando forte redução.

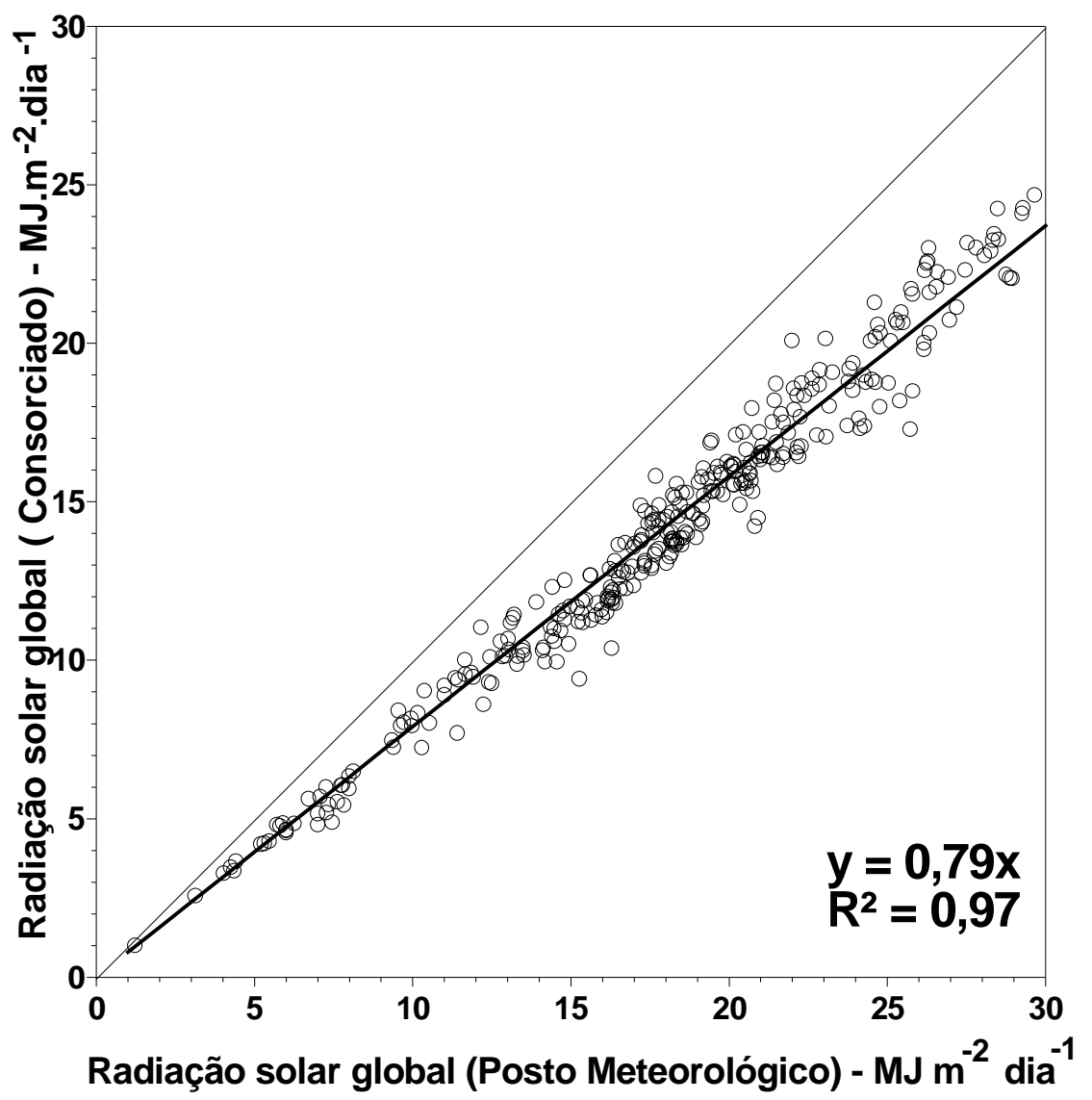

Figura 4. Comparação entre os valores diários da radiação solar global $\left(\mathrm{MJm}^{-2} \mathrm{dia}^{-1}\right)$ em cultivo de café a pleno sol e consorciado com bananeira Prata Anã (média dos pontos amostrais), em Mococa (SP), no período de outubro de 2001 a setembro de 2002 . 
Tabela 2. Dados mensais do saldo de radiação (SR - MJ.m $\mathrm{m}^{-2} \cdot$ dia $^{-1}$ ) em um cultivo de café a pleno sol e em diferentes pontos amostrais de cultivo de café consorciado com bananeira Prata Anã, em Mococa (SP), no período de outubro de 2001 a setembro de 2002

\begin{tabular}{|c|c|c|c|c|c|}
\hline \multirow{3}{*}{ Mês } & \multirow{3}{*}{ Pleno sol } & \multicolumn{4}{|c|}{ Saldo de radiação $\left(\mathrm{MJ} \mathrm{m}^{-2}\right.$ dia $\left.^{-1}\right)$} \\
\hline & & \multicolumn{4}{|c|}{ Cultivo consorciado } \\
\hline & & Ponto 1 & Ponto 2 & Ponto 3 & Média (1) \\
\hline Outubro & 12,0 & 10,3 & 12,5 & 11,5 & 11,5 \\
\hline Novembro & 11,6 & 10,8 & 12,9 & 11,7 & 11,8 \\
\hline Dezembro & 10,7 & 6,3 & 12,0 & 10,7 & 9,7 \\
\hline Janeiro & 12,4 & 4,8 & 13,7 & 12,6 & 10,4 \\
\hline Fevereiro & 9,4 & 3,1 & 9,7 & 9,7 & 7,5 \\
\hline Março & 11,4 & 3,1 & 10,4 & 11,9 & 8,5 \\
\hline Abril & 9,4 & 1,8 & 8,7 & 9,5 & 6,7 \\
\hline Maio & 6,0 & 1,4 & 6,3 & 5,9 & 4,5 \\
\hline Junho & 5,6 & 2,2 & 5,8 & 5,0 & 4,4 \\
\hline Julho & 4,9 & 1,2 & 5,8 & 4,7 & 3,9 \\
\hline Agosto & 6,4 & 1,5 & 7,7 & 6,2 & 5,2 \\
\hline Setembro & 8,00 & 3,1 & 7,2 & 8,1 & 6,2 \\
\hline
\end{tabular}

( $\left.{ }^{1}\right)$ Média dos pontos de leitura dentro da parcela consorciada.

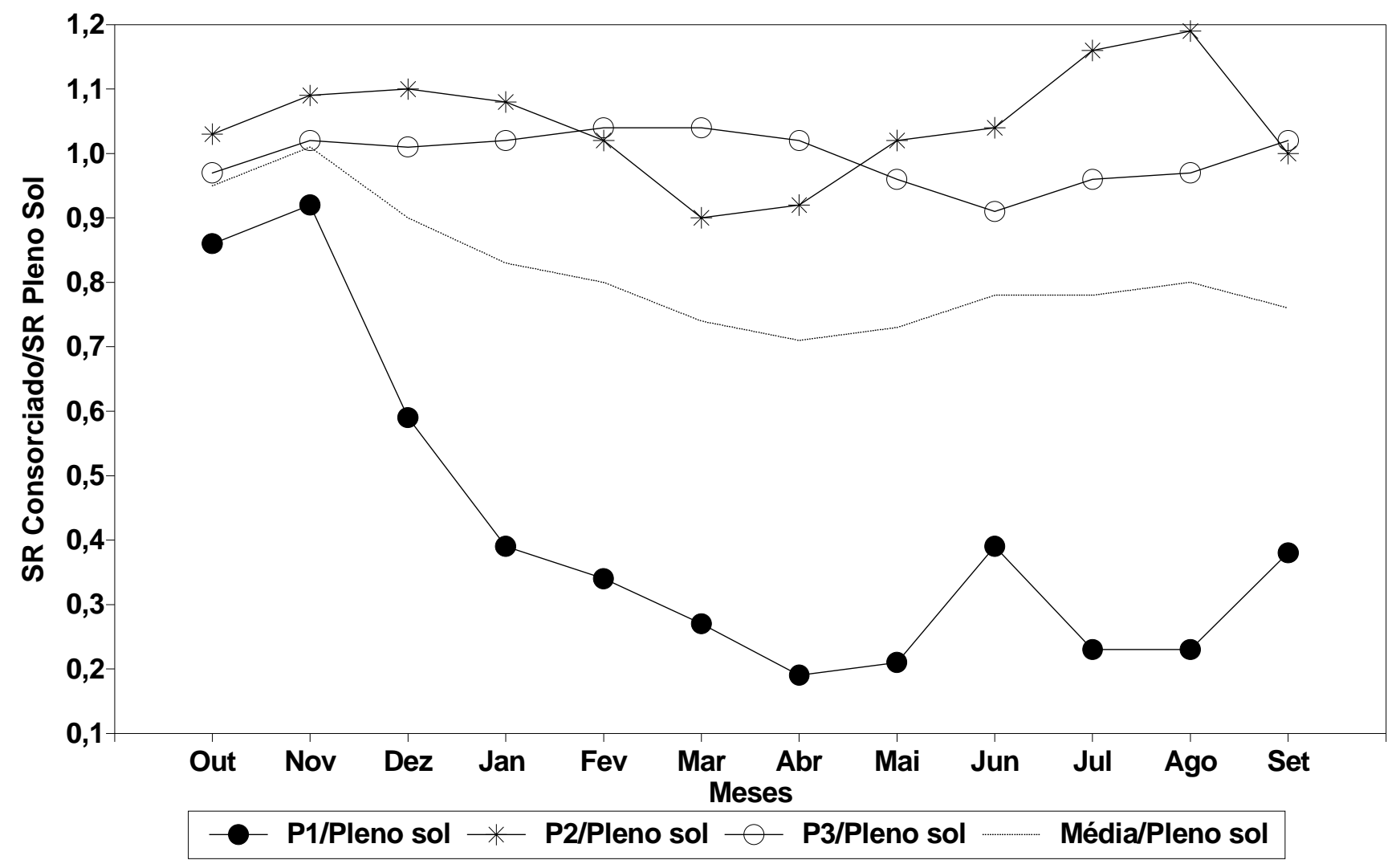

Figura 5. Variação sazonal da relação entre o Saldo de Radiação em diferentes pontos amostrais de cultivo de café consorciado (SR consorciado) e o Saldo de Radiação no cultivo a Pleno Sol (SR Pleno sol), no período de outubro de 2001 a setembro de 2002, em Mococa (SP). 
Nos pontos de observação 2 e 3 do sistema consorciado, essa redução foi bem menos significativa, e, para o ponto 2 , situado entre duas bananeiras, na maioria dos meses o SR permaneceu acima do cultivo a pleno sol. No período de outubro a fevereiro, o SR no ponto 2 do sistema consorciado permaneceu, em média diária, cerca de $10 \%$ a $20 \%$ superior em relação ao cultivo a pleno sol, e as maiores diferenças foram em dias nublados, com baixa incidência de radiação solar. Fato semelhante ocorreu em julho e agosto. No ponto 3 do sistema consorciado, os valores de SR permaneceram próximos aos do cultivo a pleno sol na maioria dos meses do ano, com reduções ou incrementos de SR inferiores a $10 \%$.
Analisando os dados médios do três sensores do sistema consorciado, verificou-se que o SR permaneceu sempre acima de $70 \%$ em relação ao cultivo a pleno sol, influenciado principalmente pelos valores do ponto de observação 1 .

Para melhor representação da influência do sistema consorciado no saldo de radiação, foram selecionados quatros episódios ao longo do ano, sendo dois com céu limpo e dois com céu nublado que estão apresentados na figura 6 e na tabela 3 , com os valores do saldo de radiação selecionados em período diurno (6 às 18 horas) e período noturno (18 e 6 horas).
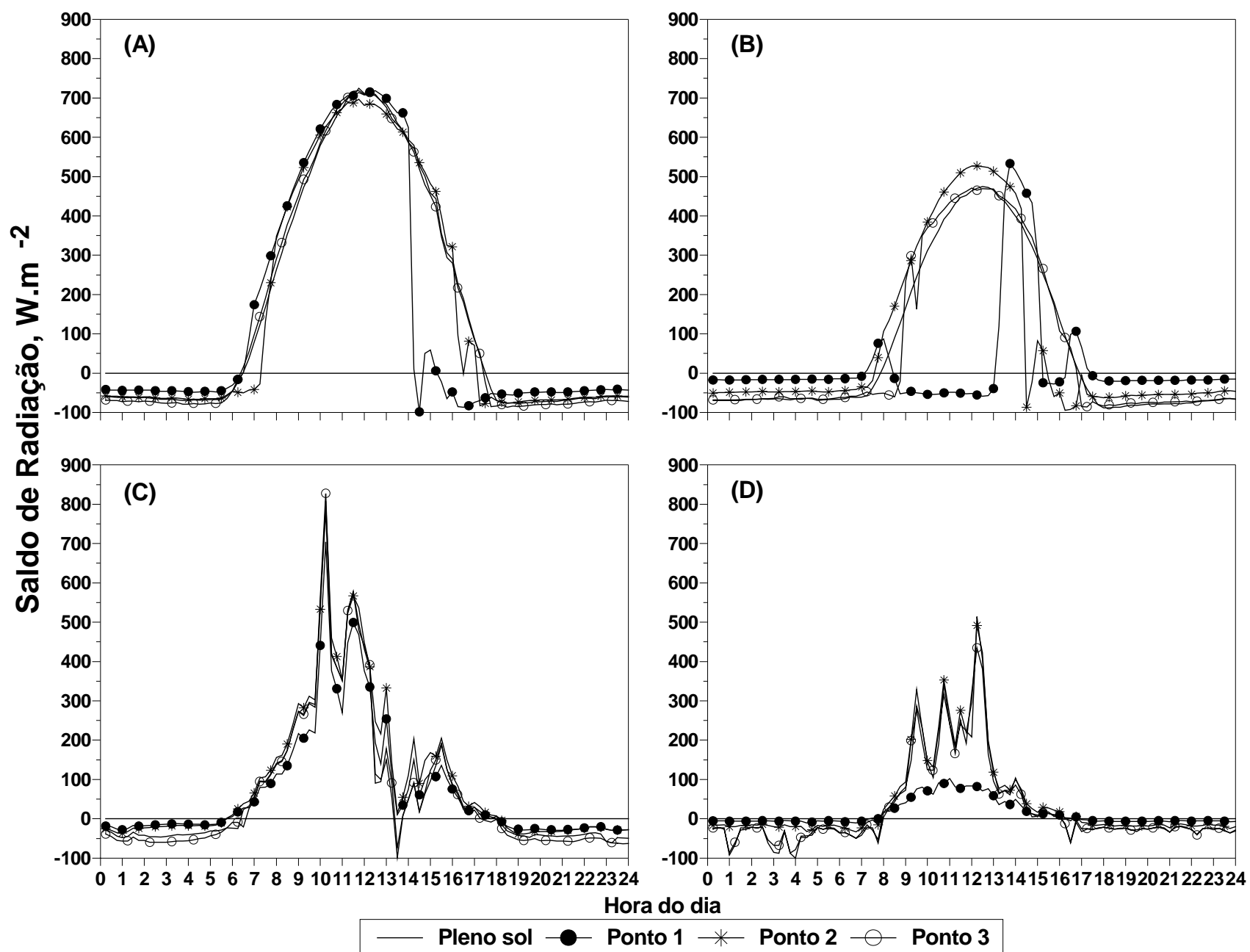

Figura 6. Variação dos valores horários do saldo de radiação em cultivo de café a pleno sol e em diferentes pontos amostrais de cultivo de café consorciado com banana Prata Anã, em Mococa (SP) em 28/10/2001 (A), 26/7/2002 (B), característicos de céu limpo e 23/11/2001 (C) e 23/7/2002 (D), nublados. 
Tabela 3. Valores diários do saldo de radiação $\left(\mathrm{MJ} \mathrm{m}^{-2} \mathrm{dia}^{-1}\right)$ em um cultivo de café a pleno sol e em diferentes pontos amostrais de café consorciado com bananeira Prata Anã, em Mococa (SP), para quatro episódios selecionados

\begin{tabular}{|c|c|c|c|c|c|c|c|c|}
\hline \multirow{3}{*}{ Dia } & \multirow{3}{*}{ Período ${ }^{(1)}$} & \multicolumn{4}{|c|}{ Saldo de radiação $\left(\mathrm{MJ} \mathrm{m}^{-2}\right)$} & & & \\
\hline & & \multirow[t]{2}{*}{ Pleno sol } & \multicolumn{3}{|c|}{ Consorciado } & \multicolumn{3}{|c|}{ Razão de SR ${ }^{(2)}$} \\
\hline & & & P1 & $\mathrm{P} 2$ & P3 & P1/sol & $\mathrm{P} 2 /$ sol & $\mathrm{P} 3 / \mathrm{sol}$ \\
\hline \multirow{3}{*}{$28 / 10 / 2001$} & Diurno & 17,21 & 14,17 & 16,70 & 17,32 & 0,82 & 0,97 & 1,01 \\
\hline & Noturno & $-2,83$ & $-1,95$ & $-2,72$ & $-3,21$ & 0,69 & 0,96 & 1,14 \\
\hline & Total & 14,39 & 12,21 & 13,98 & 14,12 & 0,85 & 0,97 & 0,98 \\
\hline \multirow{3}{*}{$23 / 11 / 2001$} & Diurno & 7,57 & 7,05 & 9,08 & 7,65 & 0,93 & 1,20 & 1,01 \\
\hline & Noturno & $-1,73$ & $-0,89$ & $-1,06$ & $-2,21$ & 0,51 & 0,61 & 1,28 \\
\hline & Total & 5,84 & 6,16 & 8,02 & 5,43 & 1,06 & 1,37 & 0,93 \\
\hline \multirow{3}{*}{$23 / 7 / 2002$} & Diurno & 3,54 & 1,44 & 4,27 & 3,48 & 0,41 & 1,21 & 0,98 \\
\hline & Noturno & $-1,51$ & $-0,26$ & $-0,78$ & $-1,44$ & 0,17 & 0,51 & 0,95 \\
\hline & Total & 2,03 & 1,18 & 3,49 & 2,04 & 0,58 & 1,72 & 1,01 \\
\hline \multirow{3}{*}{$26 / 7 / 2002$} & Diurno & 8,96 & 2,40 & 8,68 & 8,80 & 0,27 & 0,97 & 0,98 \\
\hline & Noturno & $-3,05$ & $-0,74$ & $-2,14$ & $-2,94$ & 0,24 & 0,70 & 0,96 \\
\hline & Total & 5,90 & 1,65 & 6,54 & 5,86 & 0,28 & 1,11 & 0,99 \\
\hline
\end{tabular}

$\left({ }^{1}\right)$ Período diurno: entre 6 e 18 horas; Período noturno: entre 18 e 6 horas; Total: total diário.

$\left({ }^{2}\right)$ Relação entre o saldo de radiação do ponto amostral (Pn) no cultivo consorciado e o saldo de radiação no cultivo a pleno sol.

Em 28/10/2001 (Figura 6A), observou-se na curva do saldo de radiação um padrão típico verificado em superfícies vegetais, em condições de céu aberto em dia claro, com o SR no cultivo a pleno sol, atingindo cerca de $700 \mathrm{~W} \mathrm{~m}^{-2}$ ao meio dia e total de $17,21 \mathrm{MJ} \mathrm{m}^{-2}$ para período diurno. No cultivo consorciado, os valores foram próximos, com menor incidência no ponto 1 , com $82 \%$ de transmissividade em relação ao cultivo a pleno sol, afetada principalmente no período vespertino. No período noturno, o saldo foi negativo, resultado do balanço negativo entre a radiação emitida pela superfície (radiação terrestre) e a contra-radiação (atmosférica). No ponto 1 do sistema consorciado, como esperado, ocorreram menores valores absolutos, devido à menor perda energética proporcionada por trocas radiativas com as folhas de bananeira. CARAMORI et al. (1996), assim como BRENNER (1996) também verificaram o efeito protetor de árvores utilizadas em cultivos arborizados.

Para o dia 26/7/2002, também em condição de céu limpo, a influência das plantas de banana foram mais significativas com relação à transmissividade, mesmo para o período diurno. Em determinados períodos do dia, o SR foi maior na parcela consorciada do que no cultivo a pleno sol, principalmente para os pontos 2 e 3 no período matutino e ponto 1 no período vespertino, provavelmente quando o sensor recebia contribuição de contra-radiação emitida pelas folhas das bananeiras. Nesse dia, para o período diurno, o SR do ponto 2 do sistema consorciado praticamente igualou o SR do cultivo a pleno sol. No período noturno pôde ser verificado, como em 28/10/2001, menores perdas radiativas dos pontos da parcela consorciada em relação ao cultivo a pleno sol. Diante disso, no total diário, o SR no ponto 2 do sistema consorciado foi $11 \%$ maior do que o cultivo a pleno sol.

Nos dias característicos de céu nublado, 23/ $11 / 2001$ e $23 / 7 / 2002$, o total diário de SR sobre as parcelas experimentais foi menor, totalizando 5,84 e 2,03 $\mathrm{MJ} \mathrm{m}^{-2} \mathrm{dia}^{-1}$, respectivamente no cultivo a pleno sol (Tabela 3). Nos dois episódios, o SR no ponto 2 de leitura do cultivo consorciado, situado entre duas bananeiras, superou em $20 \%$ a incidência do cultivo a pleno sol no período diurno, enquanto no período noturno ocorreu menor perda radiativa, ocasionando valores superiores de SR em relação ao cultivo a pleno sol, de $37 \%$ e $72 \%$ respectivamente. Em cultivos arborizados, ocorre um aumento na proporção de radiação difusa, com característica multidirecional e de baixa energia, que incide sobre a cultura protegida (VANDEnBeldt e Williams, 1992), o que se torna ainda mais evidente em dias nublados. É importante ressaltar que ocorrências de episódios como o de 23/ $7 / 2002$ promoveram aumento de cerca de $20 \%$ nos valores médios diários de SR no ponto 2 do sistema consorciado em relação ao sistema a pleno sol em julho (Figura 6). 
Para os mesmos episódios, o comportamento do SR no ponto 1 do sistema consorciado foi diferente, com baixa incidência no dia 23/7/2002, provavelmente porque as folhas da bananeira sobre o sensor interceptaram grande parte da radiação incidente. No ponto amostral 3 do sistema consorciado, na parte central da parcela, a incidência foi próxima do cultivo a pleno sol, com razão de incidência perto da unidade tanto nos valores diurnos quanto noturnos.

A comparação dos valores diários obtidos de SR (cultivo a pleno sol) e nos diferentes pontos de medição da parcela consorciada (média dos pontos amostrais), está na figura 7 .

O coeficiente angular $(0,84)$ indica uma redução da transmissividade média no ano de $16 \%$, promovida pelas plantas de bananeira no cultivo consorciado. Esses valores foram influenciados principalmente pelo ponto amostral 1 do sistema consorciado, situado próximo à bananeira. Em dias com baixa incidência de radiação, com até $6 \mathrm{MJ} \mathrm{m}^{-2} \mathrm{dia}^{-1}$ de saldo de radiação, como verificado nos episódios com céu nublado na figura 6C e 6D e Tabela 3, o saldo de radiação no sistema consorciado superou o SR no cultivo a pleno sol, influenciado principalmente pela menor perda de radiação de onda longa para a atmosfera.
Uma importante informação relacionada com o balanço de radiação em cultivos agrícolas é a relação entre o saldo de radiação da cultura (SR) e a radiação solar global (RG), apresentada para os dois sistemas de cultivo em sua variação mensal na tabela 4 , e na figura 8, para janeiro e julho.

Para o cultivo a pleno sol, a relação entre o SR/RG variou de 0,62 em janeiro, a 0,34 em julho (Tabela 4). Para o cultivo consorciado a relação variou de 0,68 em novembro a 0,35 em julho (Tabela 4). Quando analisado todo o período de medição, o SR representou $50 \%$ e $53 \%$ de RG nos cultivos a pleno sol e consorciado respectivamente .

Sentelhas e Nascimento (2003), em estudo de relação SR/RG para um gramado em Piracicaba, observaram variação anual da relação de 0,59 em fevereiro a 0,47 em maio, relacionando como principais causas dessa variação sazonal o maior coeficiente de reflexão da superfície gramada no período seco, além da nebulosidade e umidade do ar associados ao regime de chuvas. Segundo esses autores, as variáveis interferem no balanço de ondas, havendo redução da perda de radiação na faixa de infravermelho termal sob condições de alta umidade do ar e com a presença de nuvens, o que resulta em maior saldo de radiação diário, aumentando a relação de SR/RG, como o ocorrido em janeiro nos dois sistemas de cultivo de café deste experimento (Figura 8).

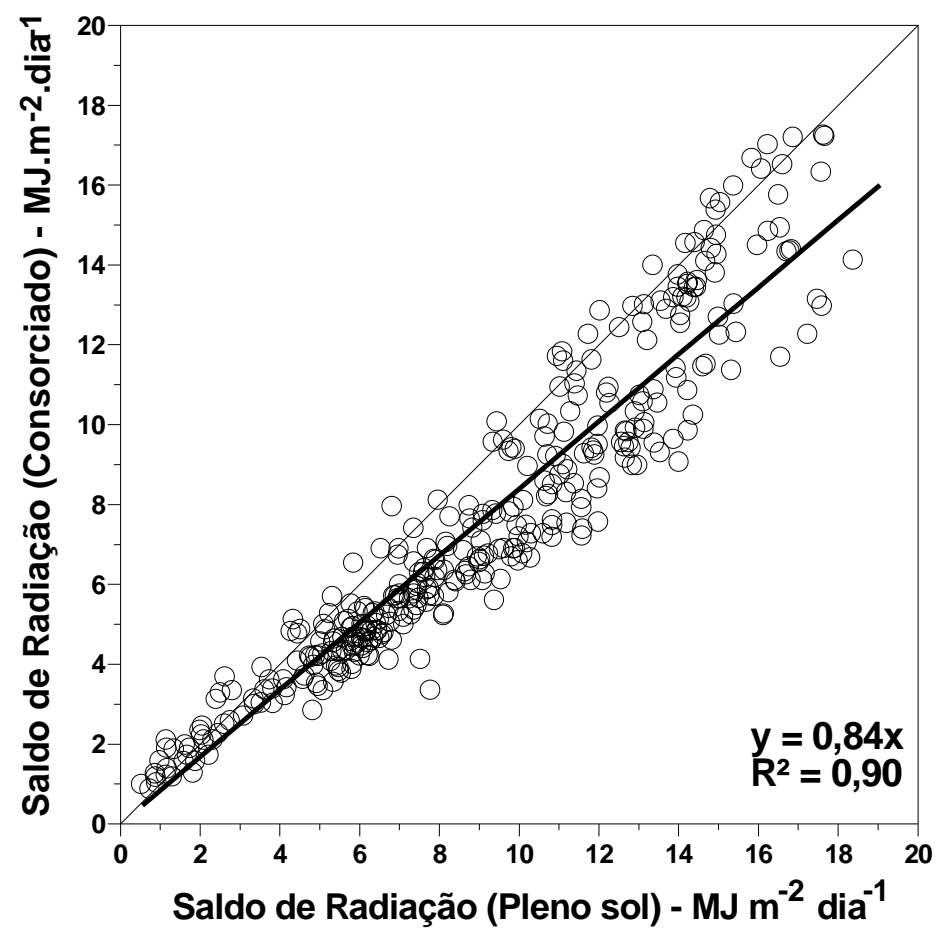

Figura 7. Relação entre os valores diários do saldo de radiação ( $\mathrm{MJ} \mathrm{m}^{-2} \mathrm{dia}^{-1}$ ) em cultivo de café a pleno sol e em cultivo de café consorciado com bananeira Prata Anã (média dos pontos amostrais), em Mococa (SP), no período de outubro de 2001 a setembro de 2002. 
Tabela 4. Variação sazonal das relações entre saldo de radiação diário (SR) e radiação solar global (RG) nos cultivos de café a pleno sol e consorciado com bananeira Prata Anã, em Mococa (SP), no período de outubro de 2001 a setembro de 2002. Valores entre parênteses indicam o $R^{2}$.

\begin{tabular}{lcc}
\hline Mês & SR/RG & $\begin{array}{c}\text { SR/RG } \\
\text { Café consorciado }\end{array}$ \\
\hline Outubro & $0,54(0,90)$ & $0,62(0,93)$ \\
Novembro & $0,57(0,94)$ & $0,68(0,98)$ \\
Dezembro & $0,58(0,93)$ & $0,64(0,93)$ \\
Janeiro & $0,62(0,97)$ & $0,64(0,83)$ \\
Fevereiro & $0,57(0,94)$ & $0,61(0,96)$ \\
Março & $0,55(0,93)$ & $0,53(0,91)$ \\
Abril & $0,47(0,68)$ & $0,43(0,69)$ \\
Maio & $0,41(0,79)$ & $0,41(0,86)$ \\
Junho & $0,36(0,62)$ & $0,38(0,55)$ \\
Julho & $0,34(0,80)$ & $0,35(0,72)$ \\
Agosto & $0,39(0,83)$ & $0,39(0,83)$ \\
Setembro & $0,47(0,93)$ & $0,44(0,83)$ \\
Ano & $0,50(0,81)$ & $0,53(0,75)$ \\
\hline
\end{tabular}

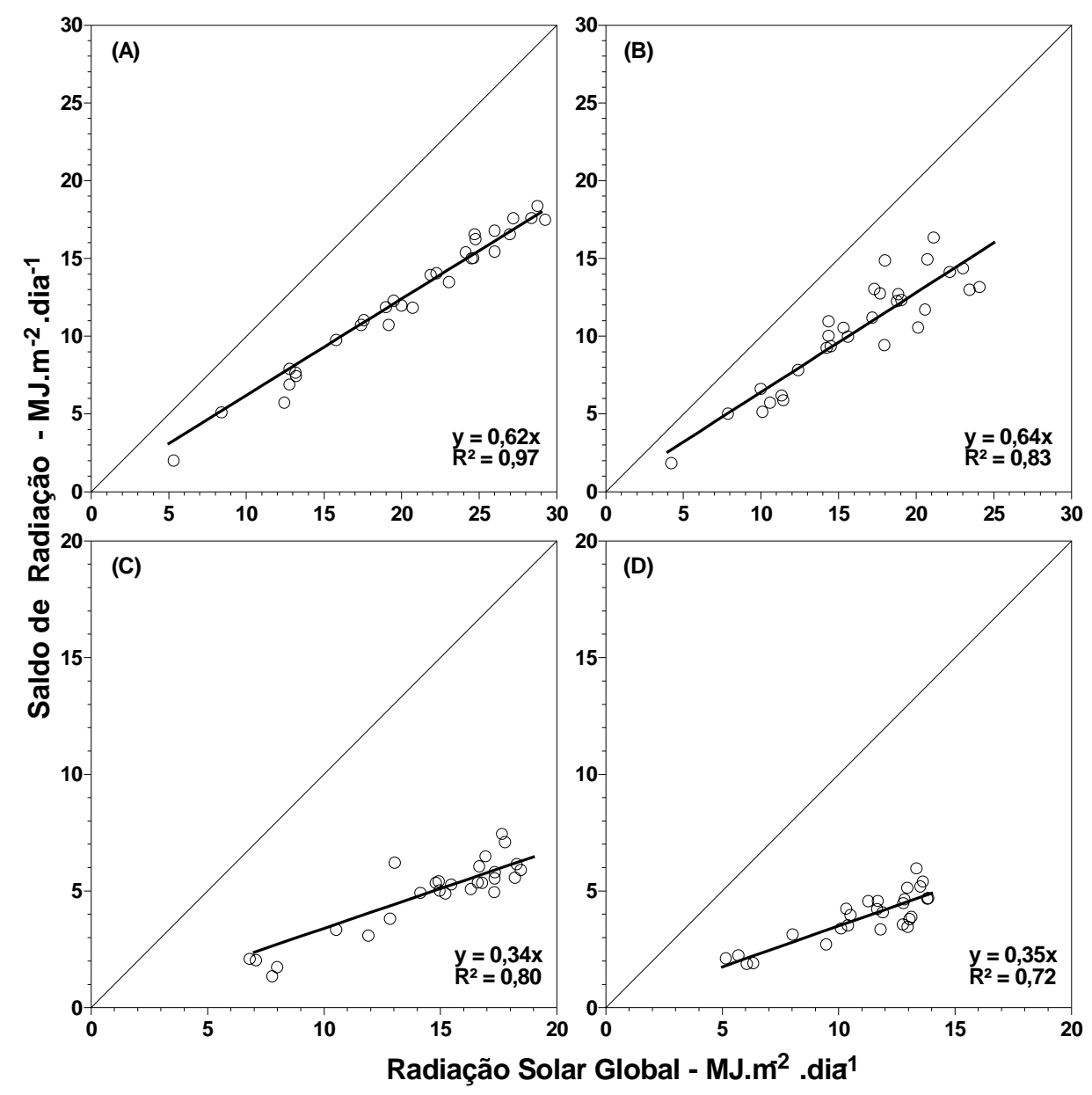

Figura 8. Comparação entre os valores diários do saldo de radiação e a radiação solar global no cultivo de café a pleno sol nos meses de janeiro (A) e junho (C) de 2002 e consorciado com bananeira Prata Anã, em janeiro (B) e julho (D) de 2002, em Mococa (SP). 
Em julho, ocorreu a menor relação SR/RG nos dois sistemas de cultivo. Segundo Sentelhas e NAsCimento (2003), em meses com fotoperíodo menor que 12 horas, ocorre significativa elevação dos valores negativos do saldo de radiação, o que contribui para a diminuição das relações de SR/RG, como ocorrido em 26/7/2002 (Figura 6B e Tabela 3).

Nas relações de SR/RG no período de outubro a fevereiro, observaram-se maiores diferenças entre os dois sistemas de cultivos, com maiores valores para o sistema consorciado (Tabela 4), devido principalmente ao maior saldo de radiação em dias chuvosos, como apresentado na Tabela 3 para 23/11/ 2002, além da menor perda radiativa no sistema consorciado no período noturno, o que proporciona maiores valores de saldo de radiação. Também em conseqüência, a relação média de SR/RG no sistema consorciado (53\%) foi maior que no cultivo a pleno sol (50\%).

MARIN (2003) destaca que essa informação, apesar de ser de fácil aplicação, não pode ser extrapolada para qualquer cafezal, mas apenas para aqueles cultivados em espaçamentos semelhantes e em mesma condição de porte.

Para cultivos de café, JARAMILLO-Robledo (1994) observou a relação SR/RG, no período diurno, para a cv. Caturra com uma população de 10.000 plantas ha $^{-1}$, igual a 0,74 . Pezzopane et al. (2001) verificaram a relação de $S R / R G$ para valores diários, de 0,61 para a cv. Obatã com uma população de 10.000 plantas por hectare e MARIN (2003) observou a relação SR/RG igual a 0,49 para um cafezal da cv. Mundo Novo com uma população de 4000 plantas por hectare em setembro e outubro, deduzindo que a população de plantas, porte da planta e época do ano, além da cobertura vegetal da entrelinha têm influência na determinação dessa relação.

\section{CONCLUSÕES}

1. Houve atenuação média dos valores de radiação solar global em cultivo de café consorciado com banana Prata Anã da ordem de 21\%, com variação mensal de $16 \%$ a $27 \%$.

2. Verificou-se redução média de $16 \%$ nos valores diários do saldo de radiação no cultivo consorciado em relação ao cultivo a pleno sol.

3. O saldo de radiação representou $50 \%$ da radiação solar global no cultivo a pleno sol, com variação mensal de $34 \%$ a $62 \%$, e no cultivo consorciado o saldo de radiação representou $53 \%$ da radiação solar global, com variação de $35 \%$ a $38 \%$.

\section{REFERÊNCIAS}

BAGGIO, A.J.; CARAMORI, P.H.; ANDROCIOLI, A.; MONTOYA, L. Productivity of southern Brazilian coffee plantations shaded by different stockings of Grevillea robusta. Agroforestry Systems, Amsterdam, v. 37, n. 2, p.111-120, 1997.

BARRADAS, V.L.; FANJUL, L. Microclimatic characterization of shaded and open-grow coffee (Coffea arabica L.) plantations in Mexico. Agricultural and Forest Meteorology, Amsterdam, v. 38, p. 101-112, 1986.

BEER, J. Advantages, disadvantages and desirable characteristics of shade trees for coffee, cacao and tea. Agroforestry Systems, Amsterdam, v. 5, p. 3-13, 1987.

BEER, J.; MUSCHLER, R.; KASS, D.; SOMARRIBA, E. Shade management in coffee and cacao plantations. Agroforestry Systems, Amsterdam, v. 38, p. 139-164, 1998.

BLACK, C.; ONG, C. Utilizations of light and water in tropical agriculture. Agricultural and Forest Meteorology, Amsterdam, v. 104, n.1, p. 25-47, 2000.

BRENNER, A.J. Microclimatic modifications in agroforestry. In: ONG, C.K., HUXLEY, P. (Ed.) Tree-crop interactions: A physiological approach. Cambridge: University Press, 1996. cap. 5, p. 159-188.

CAMARGO, A.P.; PEREIRA, A.R. Agrometeorology of the coffee crop. In: WORLD Meteorological Organization. Geneva: WMO/TD, 1994. n. 615, 43 p.

CARAMORI, P.H.; ANDROCIOLI FILHO, A.; LEAL, A.C. Coffee shade with Mimosa scabrella Benth. for frost protection in southern Brazil. Agroforestry Systems, Amsterdam, v. 33, p. 205-214, 1996.

CARVALHO, A.; KRUG, C.A.; MENDES, J.E.T.; ANTUNES FILHO, H.; REIS, A.J.; ALOISI SOBRINHO, J.; ROCHA, T.R.; MORAES, M.V. Melhoramento do cafeeiro. XXI. Comportamento regional de variedades, linhagens e progênies de café ao sol e à sombra. Bragantia, Campinas, v. 20, p. 1045-1142, 1961.

FARFAN-VALENCIA, F.; ARIAS-HERNANDEZ, J.J.; RIANOHERRERA, N.M. Deasarrollo de una metodologia para medir sombrio en sistemas agroflorestales com café. Cenicafé, Chinchina. 54, n.1, p. 24-34, 2003.

JARAMILLO-ROBLEDO, A. Aspectos microclimaticos en plantaciones de café (Coffea arabica L.) com alta densidad de siembra. In: SIMPÓSIO INTERNACIONAL SOBRE CAFÉ ADENSADO, 1., Londrina, 1994. Anais. Londrina: IAPAR, 1994. P. 47-69.

MARIN, F.R. Evapotranspiração e transpiração máxima em cafezal adensado. 2003. 118 f. Tese (Doutorado) - Escola Superior de Agricultura "Luiz de Queiroz", Universidade de São Paulo, Piracicaba. 
MATIELLO, J.B.; ALMEIDA, S.R. Sistemas de combinação de café com seringueira, no sul de Minas Gerais. In: CONGRESSO BRASILEIRO DE PESQUISAS CAFEEIRAS, 17., Varginha, 1991. Trabalhos apresentados... Rio de Janeiro: MARA/SNPA/ EMBRAPA, 1991.p. 112-114.

MIGUEL, A.E.; MATIELLO, J.B.; CAMARGO, A.P.; ALMEIDA, S.R.; GUIMARÃES, S.R. Efeitos da arborização do cafezal com Grevillea robusta nas temperaturas do ar e umidade do solo, Parte II. In: CONGRESSO BRASILEIRO DE PESQUISAS CAFEEIRAS, 21., Rio de Janeiro, 1995. Trabalhos apresentados... Rio de Janeiro: PROCAFE, 1995. p. 55-60

MOREIRA, R.S. Banana: Teoria e práticas de cultivo. Campinas: Fundação Cargill, 1987. 335 p.

PEETERS, L.Y.K.; SOTO-PINTO, L.; PERALES, H.; MONTOYA, G.; ISHIKI, M. Coffee production, timber, and firewood in traditional and Inga-shaded plantations in Southern Mexico. Agriculture, Ecossystems and Environment, Amsterdam, v. 82, p. 1-13, 2002.

PEZZOPANE, J.E.M. Caracterização microclimática, ecofisiológica e fitossociológica em uma floresta estacional semidecidual secundária em Viçosa, MG. 2001. 255 f. Tese (Doutorado) - Universidade Federal de Viçosa.

PEZZOPANE, J.R.M.; GALLO, P.B.; PEDRO JR., M.J. Radiação solar global, saldo de radiação e fluxo de calor no solo em cultivo consorciado café/coqueiro-anão verde. In: SIMPÓSIO DE PESQUISA DOSCAFÉSDO BRASIL, 2., Vitória, 2001. Resumos Expandidos. Brasília: EMBRAPA Café, 2001. p. 206-213.
PEZZOPANE, J.R.M.; GALLO, P.B.; PEDRO JÚNIOR, M.J.; ORTOLANI, A.A. Caracterização microclimática em cultivo consorciado café/coqueiro-anão verde. Revista Brasileira de Agrometeorologia, Santa Maria, v. 11, n. 2, p. 293-302, 2003.

SENTELHAS, P.C.; NASCIMENTO, A.L.C. Variação sazonal da relação entre o saldo de radiação e a radiação solar global. Revista Brasileira de Agrometeorologia, Santa Maria, v. 18, n. 1, p. 71-77, 2003.

THOMAZIELLO, R.A.; FAZUOLI, L.C.; PEZZOPANE, J.R.M.; FAHL,J.I.; CARELLI, M.L.C. Café Arábica: Cultura e técnicas de produção. Campinas: Instituto Agronômico, 2000 82p. (Boletim Técnico, 187)

VANDENBELDT, R.J.; WILLIAMS, J.H. The effect of soil surface temperature on the growth of millet in relation to the effect of Faidherbia albida trees. Agricultural and Forest Meteorology, Amsterdam, v. 60, p. 93-100, 1992

WALLACE, J.S. The water balance of mixed tree-crop systems. In: ONG, C.K., HUXLEY, P. (Ed.). Tree-crop interactions: A physiological approach. Cambridge: University Press, 1996. cap. 6, p. $189-234$. 